\title{
Oral Amodiaquine, Artesunate and Artesunate Amodiaquine Combination Affects Open Field Behaviors and Spatial Memory in Healthy Swiss Mice
}

\author{
Adejoke Yetunde Onaolapo ${ }^{1}$, Olakunle James Onaolapo ${ }^{2 *}$, Emmanuel O. Awe $^{2}$, Samuel Oloyede ${ }^{1}$, \\ Ayomide Joel ${ }^{1}$ \\ ${ }^{1}$ Department of Human Anatomy, Faculty of Basic Medical Sciences, College of Health Sciences, \\ Ladoke Akintola University, Ogbomoso, Nigeria \\ ${ }^{2}$ Department of Pharmacology, Faculty of Basic Medical Sciences, College of Health Sciences, \\ Ladoke Akintola University, Oshogbo, Nigeria \\ Email: *olakunleonaolapo@yahoo.co.uk, adegbayibiy@yahoo.com
}

Received September 7, 2013; revised October 15, 2013; accepted October 21, 2013

Copyright (C) 2013 Adejoke Yetunde Onaolapo et al. This is an open access article distributed under the Creative Commons Attribution License, which permits unrestricted use, distribution, and reproduction in any medium, provided the original work is properly cited.

\begin{abstract}
Effects of amodiaquine, artesunate and artesunate amodiaquine combination on open field novelty-induced behaviors and spatial memory in healthy mice were studied. Forty mice were used in the open field and fifty each in the radial arm maze and Y maze; mice were assigned into four or five groups of ten each, Group A served as control (distilled water), Groups B, C and D received artesunate (4 mg/ $/ \mathrm{kg})$, amodiaquine $(10 \mathrm{mg} / \mathrm{kg})$ and artesunate-amodiaquine combination (4 $\mathrm{mg} / \mathrm{kg}$ and10 mg/kg) respectively, while Group E animals (for the cognition tests) were given scopolamine (2 mg/kg). Drugs and vehicle were administered orally for three days. Results were analysed by one way analysis of variance followed by a posthoc test. Results showed that artesunate and amodiaquine either in combination or administered singly caused a significant increase in open field novelty-induced horizontal locomotion and rearing. Grooming in the open field showed increments in the artesunate alone and artesunate amodiaquine groups while significant reductions in spatial memory were also seen in the cognition models used.
\end{abstract}

Keywords: Neurobehavior; Artesunate; Amodiaquine; Antimalaria; Novelty-Induced Behaviors; Cognition

\section{Introduction}

The increasing incidence of drug-resistant parasites in a number of malaria endemic countries has resulted in artemisinin-based combination therapies (ACTs) becoming recommended the first-line treatment of falciparum malaria worldwide [1]. Combination regimens are known to clear malaria rapidly, hasten recovery and reduce transmission in areas of low endemicity [2].

Artesunate amodiaquine (AA) is one of two commonly used ACTs available, the other being artesunate lumefantrine. AA is available in a number of formulations, including fixed-dose or co packaged. The efficacy of ACTs, artesunate amodiaquine combination included in the treatment of uncomplicated malaria in malaria endemic regions is well documented [3-6].

Artesunate is a derivative of artemisinin (qinghaosu)

"Corresponding author.
[7], the active principal of the Chinese herb Artemisia annua $\mathrm{L}$. There is a paucity of studies that have specifically investigated the possible neurologic effects of artemisins; some clinical studies have concluded that it is well tolerated, and has a wide safety margin [8,9], whilst some others have ascribed to its used neurological symptoms ranging from coma [10] to auditory impairments [11] and motor effects [12]. Animal studies report that artemisinins induce neurotoxicity or lethality in adults or embryos irrespective of specie used (mouse, rat, dog, non nonhuman primate) [13,14]. Arteether derivative was the culprit in most cases [15-17], however, this may not completely absolve other artemisin derivatives. Therefore, continuous vigilance and long-term studies involving treatment with clinically relevant doses of artemisinin may be necessary.

Amodiaquine, a 4-aminoquinoline compound similar 
to chloroquine has been used in the treatment and prevention of malaria, as well as in the treatment of diseases such as rheumatoid arthritis and lupus erythematosus $[18,19]$. It was encouraged for use at the time only in chloroquine resistant areas [20] largely due to its propensity to induce agranulocytosis in people when administered for malaria prophylaxis.

It has its side effects, some of which could be lifethreatening. Among such are neutropenia, hepatitis and fulminant hepatic failure [21], which may lead to hepatic encephalopathy, implying that amodiaquine therapy may affect the brain in ways that may not be envisaged at the commencement of therapy. Regardless of these possible risks, its affordability and efficacy make it important in the treatment of uncomplicated malaria.

Despite widespread use of artesunate amodiaquine formulations, very little is known of the neurobehavioral or the neurological effects that may result from a combination of the two drugs either in healthy or animal models of malaria. This study intended to gain an insight into such effects.

\section{Materials and Methods}

\subsection{Equipments and Apparatus}

Electronic precision balance (Kero BL 3002, India), plastic animal cages (Empire farms, Nigeria), sterile disposable syringes (1, 5 and $10 \mathrm{ml}$ ) and needles, cotton wool, stop watch, Open field box, Radial arm and Y maze.

\subsection{Reagents and Drugs}

Artesunate amodiaquine (Camosunate $\AA$, Geineth Pharmaceuticals limited) and Diazepam (Valium ${ }^{\circledR}$ ) were purchased from the pharmacy, crushed and dissolved in measured volume of distilled water to get desired concentrations. Drugs were administered orally using a cannula.

\subsection{Animals}

Healthy adult Swiss albino mice (Empire Animal farms, Osogbo, Osun State, Nigeria) with weights ranging between 20 to $25 \mathrm{~g}$ were used. They were housed in plastic cages measuring $16 \times 12 \times 10$ inches (10 mice in each cage) with free access to food and water ad libitum. Cages were maintained under standard laboratory conditions in a well aerated room with alternating light and dark cycles of $12 \mathrm{~h}$ each and at room temperature of $25^{\circ} \mathrm{C}$. The experimental protocol was approved by the Ladoke Akintola University Animal Ethics Committee. All rules applying to animal safety and care were observed.

\subsection{Experimental Method}

A total of one hundred and forty mice were used for this study; forty for open field test and fifty each in the Y maze and radial arm maze. They were assigned into four groups (A, B, C and D) for the open field test and five groups (A, B, C, D and E) for memory tests. Group A received distilled water while groups $B, C$ and $D$ received artesunate $(4 \mathrm{mg} / \mathrm{kg})$, amodiaquine $(10 \mathrm{mg} / \mathrm{kg})$ and artesunate amodiaquine combination ( $4 \mathrm{mg} / \mathrm{kg}+10$ $\mathrm{mg} / \mathrm{kg}$ ) respectively and Group E diazepam (5 mg/kg), drugs or vehicle were administered over a 3 day period; the animals were exposed to the mazes after the first and last dose of drug or vehicle. Behavioral tests were conducted in a large quite room between the hours of 8 a.m. and 4 p.m. Effects of amodiaquine, artesunate and artesunate amodiaquine combination or vehicle on novelty induced behavior was assessed using the open field and spatial memory effects evaluated using the using the Y-maze and radial arm maze. Behaviors were scored by the authors using a stop watch; all animals in one group were tested on the same day. All events were observed and recorded manually as previously described [22].

\subsection{Statistical Analysis}

Data were analysed using one way analysis of variance (ANOVA) followed by post hoc tests (Student Newman Keul's) carried out to determine the source of a significant effect. Results were expressed as Mean \pm S.E.M., p $<0.05$ was taken as accepted level of significant difference from control.

\section{Results}

\subsection{Effect of Amodiaquine, Artesunate and Artesunate Amodiaquine Combination on Horizontal Locomotion}

Figure 1 shows the effect of amodiaquine, artesunate and artesunate amodiaquine combination on horizontal locomotion, following 30 minutes in the open field. On Day 1 there was a significant $(\mathrm{F}=27.01, \mathrm{p}<0.05)$ increase in horizontal locomotion in all treatment groups compared to control. On Day 3 there was also a significant $(\mathrm{F}=$ 363.19, $\mathrm{p}<0.05$ ) increase in horizontal locomotion in all treatment groups compared to control however animals that received artesunate amodiaquine combination showed a significant increase compared to those that received either artesunate or amodiaquine alone.

\subsection{Effect of Amodiaquine, Artesunate and Artesunate Amodiaquine Combination on Rearing Activity}

Figure 2 shows the effect of amodiaquine, artesunate and artesunate amodiaquine combination on rearing activity following 30 minutes in the open field. On Day 1 there was a significant $(F=7.27, \mathrm{p}<0.05)$ increase in rearing in animals that received artesunate or artesunate amo- 


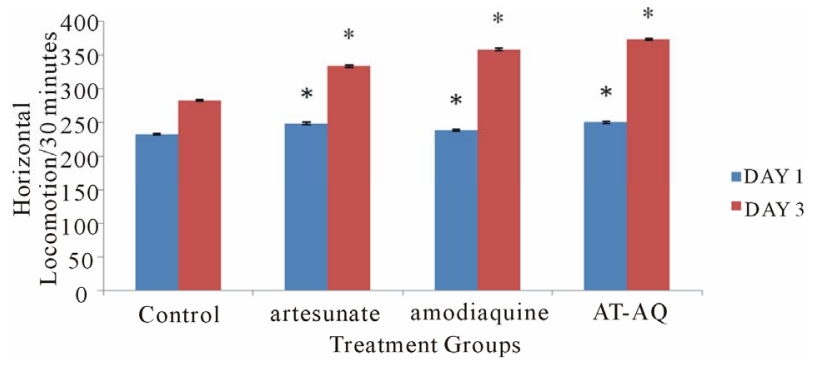

Figure 1. Effect of amodiaquine, artesunate and artesunate amodiaquine combination on horizontal locomotion following 30 minutes in the open field. Each bar represents Mean \pm S.E.M, ${ }^{*} \mathbf{p} \leq \mathbf{0 . 0 5}$ compared to the control, $n=10$.

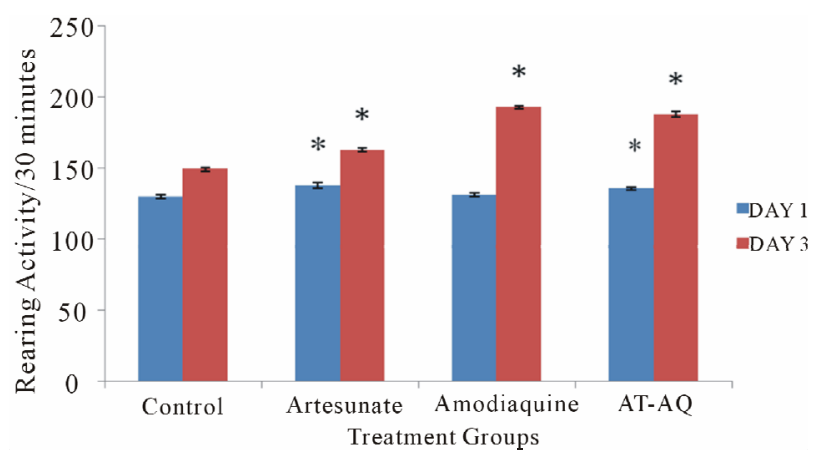

Figure 2. Effect of amodiaquine, artesunate and artesunateamodiaquine combination on rearing activity following 30 minutes in the open field. Each bar represents Mean \pm S.E.M, ${ }^{*} \mathrm{p} \leq 0.05$ compared to the control.

diaquine combination compared to control and also compared to the group that received amodiaquine alone. On Day 3 there was a significant $(\mathrm{F}=337.81, \mathrm{p}<0.05)$ increase in rearing activity in all treatment groups compared to control, animals that were given artesunate amodiaquine also showed significantly more rearing activity than those that received either artesunate or amodiaquine alone.

\subsection{Effect of Amodiaquine, Artesunate and Artesunate Amodiaquine Combination on Grooming Behavior}

Figure 3 shows the effect of amodiaquine, artesunate and artesunate amodiaquine combination on grooming behavior following 30 minutes in the open field. On Day 1, there was a significant $(\mathrm{F}=3.95, \mathrm{p}<0.05)$ increase grooming behaviour in animals that received artesunate amodiaquine combination compared to control, animals that received artesunate alone showed a slight increase compared to control, this difference was however only visual. On Day 3 there was a significant $(\mathrm{F}=55.74, \mathrm{p}<$ 0.05 ) increase in grooming activity following administration of artesunate and artesunate amodiaquine combination compared to control, animals that received artesunate-amodiaquine combination also showed a sig- nificant increase in grooming compared to those that received artesunate or amodiaquine alone.

\subsection{Effect of Amodiaquine, Artesunate and Artesunate Amodiaquine Combination on Arm Entry before First Error}

Figure 4 shows the effect of amodiaquine, artesunate and artesunate amodiaquine combination on arm entry before first error following 5 minutes in the radial arm maze. On Days $1(\mathrm{~F}=72.25, \mathrm{p}<0.05)$ and $3(\mathrm{~F}=77.85$, $\mathrm{p}<0.05)$ there were significant reduction in spatial memory tasks score in all treatment groups compared to control, although the artesunate amodiaquine group performed significantly better than groups that received either artesunate or amodiaquine alone.

\subsection{Effect of Amodiaquine, Artesunate and Artesunate Amodiaquine Combination on Total Arm Entry}

Figure 5 shows the effect of amodiaquine, artesunate and artesunate amodiaquine combination on total arm entry following 5 minutes in the radial arm maze. On Day 1 there was a significant $(\mathrm{F}=12.84, \mathrm{p}<0.05)$ increase in total arm entry in the artesunate amodiaquine group compared to control and also when compared to groups that received either artesunate or amodiaquine, while on Day 3 there was a significant $(\mathrm{F}=42.21, \mathrm{p}<0.05)$ increase in total arm entry in all treatment groups compared to control and the artesunate amodiaquine group also showed an increase in locomotor activity compared to either the artesunate or amodiaquine groups.

\subsection{Effect of Amodiaquine, Artesunate and Artesunate Amodiaquine Combination on Spatial Memory in the Y-Maze}

Figure 6 shows the effect of amodiaquine, artesunate and artesunate amodiaquine combination on spatial memory following 5 minutes of exploration in the Y maze. On

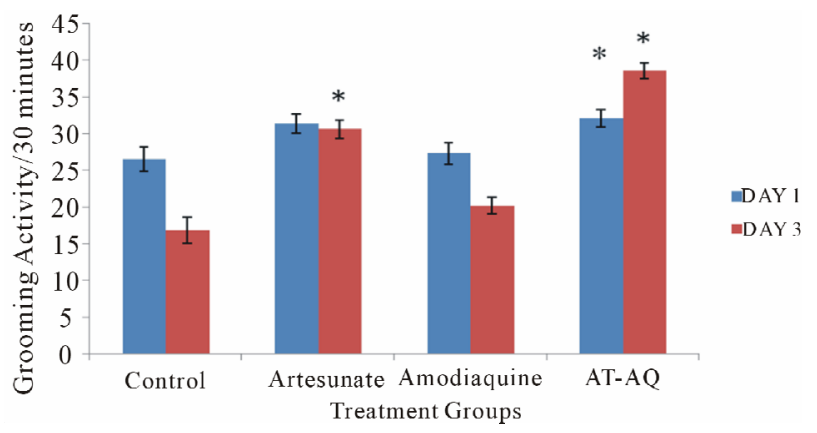

Figure 3. Effect of amodiaquine, artesunate and artesunate amodiaquine combination on grooming behaviour following 30 minutes in the open field. Each bar represents Mean \pm S.E.M, ${ }^{*} \mathbf{p} \leq \mathbf{0 . 0 5}$ compared to the control, $\mathrm{n}=10$. 


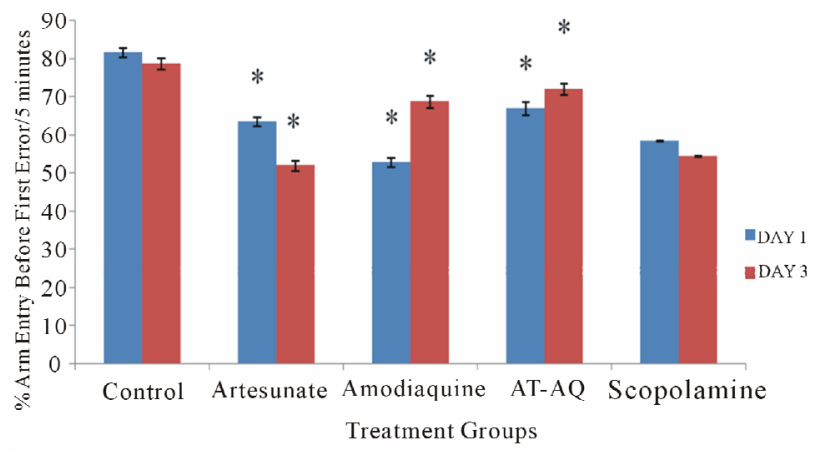

Figure 4. Effect of amodiaquine, artesunate and artesunate amodiaquine combination on arm entry before first error following 5 minutes of exploration in the radial arm maze. Each bar represents Mean \pm S.E.M, *p $\leq \mathbf{0 . 0 5}$ compared to the control, $\mathbf{n}=\mathbf{1 0}$.

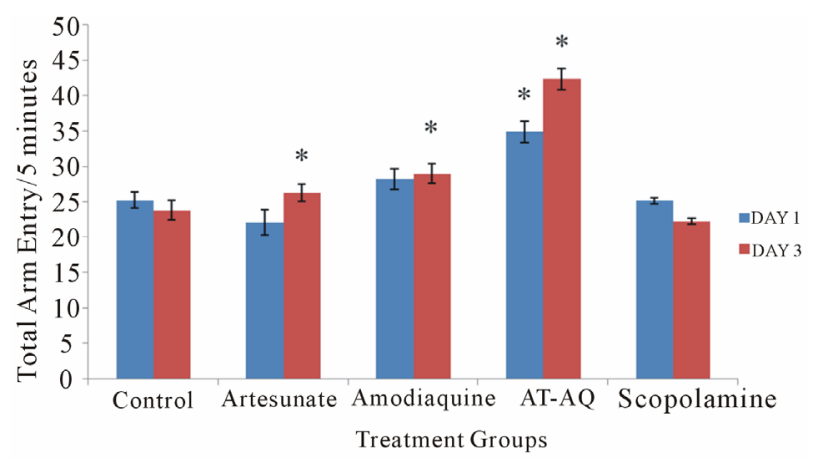

Figure 5. Effect of amodiaquine, artesunate and artesunate amodiaquine combination on total arm entry following 5 minutes of exploration in the radial arm maze. Each bar represents Mean \pm S.E.M, ${ }^{*} \mathrm{p} \leq \mathbf{0 . 0 5}$ compared to the control, $\mathbf{n}=\mathbf{1 0}$.

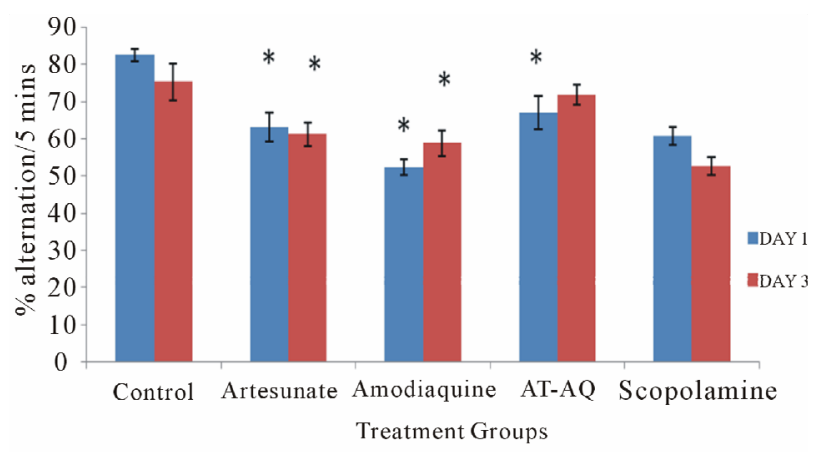

Figure 6. Effect of amodiaquine, artesunate and artesunate amodiaquine combination on spatial memory following 5 minutes of exploration in the Y-maze. Each bar represents Mean \pm S.E.M, ${ }^{*} \mathbf{p} \leq \mathbf{0 . 0 5}$ compared to the control, $\mathbf{n}=10$.

Day 1 artesunate and/or amodiaquine resulted in a significant $(\mathrm{F}=51.21, \mathrm{p}<0.05)$ reduction in spatial memory compared to control, animals that were administered amodiaquine had the lowest scores when compared to animals that received either artesunate or artesunate amodiaquine combination. On Day $3(\mathrm{~F}=32.13$, $\mathrm{p}<0.05)$ only animals that received artesunate or amodiaquine showed a significant reduction in spatial memory compared to control, those that were administered artesunate amodiaquine combination showed a slight reduction which was only visual although they showed a signifycant improvement on spatial memory scores compared to either those that received artesunate or amodiaquine alone.

\subsection{Effect of Amodiaquine, Artesunate and Artesunate Amodiaquine Combination on Locomotor Activity in the Y-Maze}

Figure 7 shows the effect of amodiaquine, artesunate and artesunate amodiaquine combination on locomotor activity following 5mins of exploration in the $\mathrm{Y}$ maze. On Days $1(\mathrm{~F}=10.54, \mathrm{p}<0.05)$ and $3(\mathrm{~F}=17.93, \mathrm{p}<0.05)$ only animals that received artesunate amodiaquine combination showed a significant increase in locomotor activity compared to control, this is also seen when they are compared to animals that received either artesunate or amodiaquine.

\section{Discussion}

The present study set out to assess the effects of amodiaquine, artesunate and artesunate amodiaquine combination on open field novelty-induced behaviors and spatial memory in healthy Swiss albino mice. Malaria is a major public health problem affecting approximately 500 million people [23], with over 1 - 2 million deaths annually mostly children in sub-Saharan Africa [24]. The increasing endemicity and resistance to treatment has resulted in the use of combination therapies; one of such is artesunate amodiaquine combination [1]. In the study, we first examined the behavioral effects of these drugs after acute administration and then after a three day daily dosing regimen; however, it must be noted that efforts at examination of the effects of these drugs using these behavioral paradigms is uncommon.

The results showed increase in horizontal locomotor

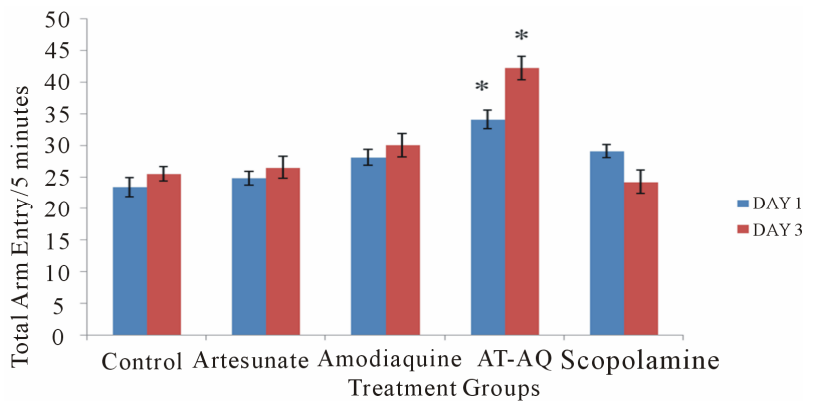

Figure 7. Effect of Artesunate Amodiaquine combination on locomotor activity following 5 minutes of exploration in the Y-maze. Each bar represents Mean \pm S.E.M, ${ }^{*} \pi \mu \alpha \mathbf{p} \leq \mathbf{0 . 0 5}$ compared to the control, $n=10$. 
and rearing activity in groups that received amodiaquine, artesunate and artesunate amodiaquine combination compared to control after acute administration and this was seen again after Day 3 of administration, administering artesunate amodiaquine combination caused a significant improvement in horizontal locomotion and rearing compared to artesunate or amodiaquine administered alone. The open field is a widely used behavioral test with horizontal locomotion and rearing being commonly recorded behaviors [25]. Both locomotor and rearing activities of rodents are central excitatory behaviors and indicative of their explorative ability [26].Increase in horizontal locomotion and rearing points to a central excitatory effect. A central excitatory effect may help us to explain some of the responses observed in human after these drugs are administered and this information helps to better our understanding of how our bodies may respond to them. Studies that try to establish how antimalaria medications may affect central nervous system neurotransmitters seem to be very scarce hence, we can only consider putative neurotransmitter interactions that may possibly explain the results seen in this study; in subsequent studies, efforts will be directed at elucidating the neural mechanisms that may underlie the observed effects. The increase in both locomotor and rearing activities seen after repeated administration of these drugs could be due to their central action on excitatory neural systems such as glutamatergic and dopaminergic systems among others or their possible downregulation of the central inhibitory systems such as $\gamma$-aminobutyric acid (GABA), also of importance is the fact that both horizontal and vertical components of locomotor activity in mice were increased during the cause of study, this may be a direct consequence of antagonism at ventral and dorsal striatum adenosine A2A receptors respectively, since an activation of dopaminergic transmission in the nucleus accumbens has been linked to locomotor hyperactivity whereas the caudate-putamen plays an important role in rearing behavior [27].

Grooming is a very important and ancient behavior observed in many animals [28]. It serves a wide range of purposes that extend well beyond the primary goal of hygiene and body care, including thermoregulation, chemo-communication, social interaction and stress reduction [29]. Grooming behavior is regulated by multiple brain regions as well as by neuromediators, hormones and drugs [30,31]. In this study, administration of three antimalaria agents resulted in increased grooming behaviors with the highest scores seen in groups that received artesunate amodiaquine combination and the lowest in the group that received amodiaquine alone. Pelage cleaning in laboratory rodents can be seen following exposure to novelty [32], It known that central dopaminergic activation induces intense grooming via
D1 receptors [33], the GABA system has also been reported to play a role in the expression of novelty-induced grooming via its GABA A and GABA B receptors [31] this it does by reducing grooming behavior so drugs that inhibit GABA may cause an increase in grooming. It is therefore possible that the drugs administered have the capability to either stimulate central dopaminergic receptors or suppress GABA receptors by a yet unknown mechanism. The sum of the effects of the drugs on openfield is that of a central excitatory effect putatively due to central dopaminergic stimulation probably with or without GABAergic suppression.

The Y-maze is a behavioral model that can be used to investigate locomotor activity as well as learning and memory; it assesses hippocampus-dependent navigational behaviors of rodents [34]. The radial arm maze is an appetitive motivated task useful in assessing spatial reference as well as spatial working memory performance and factors affecting these processes [35]. The results of both the $\mathrm{Y}$ maze and radial arm maze studies showed a reduction in spatial memory scores in all groups that received drug compared to vehicle, although the artesunate amodiaquine group performed better than either the artesunate or amodiaquine groups. This effect of artesunate amodiaquine combination on spatial memory task is for us a source of curiosity as it is obvious from the study that when combined, these drugs show less impairment of cognition than when used singly. The neurotransmitter acetylcholine (ACh) is known to be important in learning and memory processes in the hippocampus. Cholinergic activity in the hippocampus is correlated with memory, with lower than normal activity associated with spatial memory impairment as shown with drugs that impair cholinergic transmission. In the study, the memory impairments seen after administering these drugs is comparable to that seen in scopolamine group, and while we do not know the exact mechanism yet we hope that further studies will provide the answers that we need.

The results of Y maze and radial arm maze locomotor activity showed a significant increase in the artesunate amodiaquine group compared to either control or other test drugs. Changes in locomotor activity seen corresponds with what was seen in the open field, and as earlier said, increase in locomotor activity in rodents has been thought to reflect dopamine release in the striatum [36,37].

\section{Conclusion}

This study shows the ability of amodiaquine, artesunate and artesunate amodiaquine to alter novelty induced behaviors and spatial memory in healthy mice. While the emphasis of research relating to these drugs continues to be their anti-parasite effect. Neurobehavioral effects of 
antimalaria medications should also arouse the curiosity of researchers in this field.

\section{REFERENCES}

[1] T. Gordi and E. I. Lepist, “Artemisinin Derivatives: Toxic for Laboratory Animals, Safe for Humans?” Toxicology Letters, Vol. 147, No. 2, 2004, pp. 99-107. http://dx.doi.org/10.1016/j.toxlet.2003.12.009

[2] World Health Organization, "Antimalarial Drug Combination Therapy,” Report of a WHO Technical Consultation, Geneva, 2001.

[3] M. Adjuik, P. Agnamey, A. Babiker, S. Borrmann, P. Brasseur, M. Cisse, F. Cobelens, S. Diallo, J. F. Faucher, P. Garner, S. Gikunda, P. G. Kremsner, S. Krishna, B. Lell, M. Loolpapit, P. B. Matsiegui, M. A. Missinou, J. Mwanza, F. Ntoumi, P. Olliaro, P. Osimbo, P. Rezbach, E. Some and W. R. Taylor, "Amodiaquine-Artesunate versus Amodiaquine for Uncomplicated Plasmodium falciparum Malaria in African Children: A Randomised, Multicentre Trial,” The Lancet, Vol. 359, No. 9315, 2002, pp, 1365-1372.

[4] F. Abacassamo, S. Enosse, J. J. Aponte, F. X. GomezOlive, L. Quinto, S. Mabunda, A. Barreto, P. Magnussen, A. M. Ronn, R. Thompson and P. L. Alonso, "Efficacy of Chloroquine, Amodiaquine, Sulphadoxine-Pyrimethamine and Combination Therapy with Artesunate in Mozambican Children with Non-Complicated Malaria," Tropical Medicine \& International Health, Vol. 9, No. 2, 2004, pp. 200-208.

http://dx.doi.org/10.1046/j.1365-3156.2003.01182.x

[5] T. K. Mutabingwa, D. Anthony, A. Heller, R. Hallet, J. Ahmed, C. Drakeley, B. M. Greenwood and C. J. Whitty, "Amodiaquine Alone, Amodiaquine+Sulfadoxine-Pyrimethamine, Amodiaquine+Artesunate, and ArtemetherLumefantrine for Outpatient Treatment of Malaria in Tanzanian Children: A Four-Arm Randomized Effectiveness Trial,” The Lancet, Vol. 365, No. 9469, 2005, pp. 14741480. http://dx.doi.org/10.1016/S0140-6736(05)66417-3

[6] M. Martin, A. Alaribe, R. Ejemot, A. Oyo-Ita, J. Ekenjoku, C. Nwachukwu, D. Ordu and E. Ezedinachi, “Artemether-Lumefantrine versus Artesunate plus Amodiaquine for Treating Uncomplicated Childhood Malaria in Nigeria: Randomized Controlled Trial," Malaria Journal, Vol. 5, No. 43, 2006.

http://dx.doi.org/10.1186/1475-2875-5-43

[7] T. T. Hien and N. J. White, "Qinghaosu," The Lancet, Vol. 341, No. 8845, 1993, pp. 603-608. http://dx.doi.org/10.1016/0140-6736(93)90362-K

[8] R. Hutagalung, H. Htoo, P. Nwee, J. Arunkamomkiri, J. Zwang and V. I. Carrara, "A Case-Control Auditory Evaluation of Patients Treated with Artemether-Lumefantrine," The American Journal of Tropical Medicine and Hygiene, Vol. 74, No. 2, 2006, pp. 211-214.

[9] P. E. Thuma, G. J. Bhat, G. F. Mabeza, C. Osborne, G. Biemba and G. M. Shakankale, "A Randomized Controlled Trial of Arte Motil (Beta-Arteether) in Zambian Children with Cerebral Malaria," The American Journal of Tropical Medicine and Hygiene, Vol. 62, No. 4, 2000, pp. 524-529.

[10] T. H. Tran, N. P. Day, H. P. Nguyen, T. H. Nguyen, T. H. Tran and P. L. Pham, "A Controlled Trial of Artemether or Quinine in Vietnamese Adults with Severe Falciparum Malaria," The New England Journal of Medicine, Vol. 335, No. 2,1996, pp. 76-78.

http://dx.doi.org/10.1056/NEJM199607113350202

[11] S. Toovey and A. Jamieson, "Response to: Artemisinin Derivatives: Toxic for Laboratory Animals, Safe for Humans?” Toxicology Letters, Vol. 151, No. 3, 2004, pp. 491-492. http://dx.doi.org/10.1016/j.toxlet.2004.05.003

[12] L. A. Panossian, N. I. Garga and D. Pelletier, "Toxic Brainstem Encephalopathy after Artemisinins Treatment for Breast Cancer,” Annals of Neurology, Vol. 58, No. 5, 2005, pp. 812-813. http://dx.doi.org/10.1002/ana.20620

[13] R. L. Clark, T. E. K. White, S. A. Clode, I. Gaunt, P. Winstanley and S. A. Ward, "Developmental Toxicity of Artesunate and an Artesunate Combination in the Rat and Rabbit," Birth Defects Research Part B, Developmental and Reproductive Toxicology, Vol. 71, No. 6, 2004, pp. 380-394. http://dx.doi.org/10.1002/bdrb.20027

[14] G. Schmuck, A.-M. Klaus, F. Krötlinge and F. W. Langewische, "Developmental and Reproductive Toxicity Studies on Artemisone," Birth Defects Research Part B, Developmental and Reproductive Toxicology, Vol. 86, No. 2, 2009, pp. 131-143.

[15] R. F. Genovese, H. A. Nguyen and S. R. Mog, "Effects of Arteether on an Auditory Radial-Arm Maze Task in Rats," Physiology \& Behavior, Vol. 73, No. 1-2, 2001, pp. 87-91. http://dx.doi.org/10.1016/S0031-9384(01)00462-0

[16] Q. G. Li, S. R. Mog, Y. Z. Si, D. E. Kyle, M. Gettayacamin and W. K. Milhous, "Neurotoxicity and Efficacy of Arteether Related to Its Exposure Times and Exposure Levels in Rodents," The American Journal of Tropical Medicine and Hygiene, Vol. 66, No. 5, 2002, pp. 516525.

[17] Y. Si, Q. Li, L. Xie, K. Bennett, P. J. Weina and S. Mog, "Neurotoxicity and Toxicokinetics of Artelinic Acid Following Repeated Oral Administration in Rats,” International Journal of Toxicology, Vol. 26, No. 5, 2007, pp. 401-410. http://dx.doi.org/10.1080/10915810701582913

[18] C. R. Bepler, H. N. Baier, S. McCracken, C. L. Rentschler, F. B. Rogers and J. Lansbury, "A 15 Month Controlled Study of the Effects of Amodiaquine (Camoquin) in Rheumatoid Arthritis," Arthritis \& Rheumatism, Vol. 2, No. 5, 1959, pp. 403-413.

http://dx.doi.org/10.1002/1529-0131(195910)2:5<403::AI D-ART1780020505>3.0.CO;2-I

[19] H. Pomeroy, C. Warren, D. Mills and G. M, Clark, "The Effect of Amodiaquine (Camoquin) on the Course of Rheumatoid Arthritis," Arthritis \& Rheumatism, Vol. 2, No. 5, 1959, pp. 396-402.

http://dx.doi.org/10.1002/1529-0131(195910)2:5<396::AI D-ART1780020504>3.0.CO;2-T

[20] K. A. Neftel, W. Woodtly, M. Schmid, P. G. Frick and J. Fehr, "Amodiaquine Induced Agranulocytosis and Liver Disease,” British Medical Journal, Vol. 292, 1986, pp. 721-723. http://dx.doi.org/10.1136/bmj.292.6522.721

[21] L. N. Markham, E. Giostra, A. Hadengue, M. Rossier, M. 
Rebsamen and J. Desmeules, "Emergency Liver Transplantation in Amodiaquine-Induced Fulminant Hepatitis," The American Journal of Tropical Medicine and Hygiene, Vol. 77, No. 1, 2007, pp. 14-15.

[22] O. J. Onaolapo and A. Y. Onaolapo, "Subchronic Oral Bromocriptine Methanesulfonate Enhances Open Field Novelty-Induced Behavior and Spatial Memory in Male Swiss Albino Mice,” Neuroscience Journal, Vol. 2013, 2013, Article ID: 948241. http://dx.doi.org/10.1155/2013/948241.

[23] S. Yoshida, H. Nagumo, T. Yokomine, H. Araki, A. Suzuki and H. Matsuoka, "Plasmodium Berghei Circumvents Immune Responses Induced by Merozoite Surface Protein 1- and Apical Membrane Antigen 1-Based Vaccines,” PLoS One, Vol. 5, No. 10, 2010, pp. 1-10.

[24] R. W. Snow, C. A. Guerra, A. M. Noor, H. Y. Myint and S. I. Hay, "The Global Distribution of Clinical Episodes of Plasmodium falciparum Malaria,” Nature, Vol. 434, No. 7030, 2005, pp. 214-217.

[25] W. E. Crusio "Genetic Dissection of Mouse Exploratory Behavior,” Behavioural Brain Research, Vol. 125, No. 1-2, 2001, pp. 127-132. http://dx.doi.org/10.1016/S0166-4328(01)00280-7

[26] A. A. Ajayi and O. E. Ukponmwan, "Evidence of Angiotensin II and Endogenous Opioid Modulation of NIR in the Rat," African Journal of Medicine \& Medical Sciences, Vol. 23, No. 3, 1994, pp. 287-290.

[27] I. M. H. Al-Khatib, I. Doè Kmeci and M. Fujiwara, "Differential Role of Nucleus Accumbens and Caudate-Putamen in Mediating the Effect of Nomifensine and Methamphetamine Onambulation and Rearing of Rats in the Open-Field Test,” The Japanese Journal of Pharmacology, Vol. 67, No. 1, 1995, pp. 69-77. http://dx.doi.org/10.1254/jip.67.69

[28] B. D. Sachs, "The Development of Grooming and Its Expression in Adult Animals," Annals of the New York Academy of Sciences, Vol. 525, 1988, pp. 1-17. http://dx.doi.org/10.1111/j.1749-6632.1988.tb38591.x

[29] R. L. Terry, "Primate Grooming as a Tension Reduction
Mechanism,” The Journal of Psychology: Interdisciplinary and Applied, Vol. 76, No. 1, 1970, pp. 129-136. http://dx.doi.org/10.1080/00223980.1970.9916830

[30] B. M. Spruijt, J. A. van Hooff and W. H. Gispen, "Ethology and Neurobiology of Grooming Behavior,” Physiological Reviews, Vol. 72, No. 2, 1992, pp. 825-852.

[31] H. M. Barros, S. L. Tannhauser, M. A. Tannhauser and M. Tannhauser, "The Effects of GABAergic Drugs on Grooming Behaviour in the Open Field," Pharmacology \& Toxicology, Vol. 74, No. 4-5, 1994, pp. 339-344. http://dx.doi.org/10.1111/j.1600-0773.1994.tb01370.x

[32] A. J. Stoessl, “Dopamine D1 Receptor Agonist Induced Grooming Is Blocked by the Opiod Receptor Antagonist Maloxone," European Journal of Pharmacology, Vol. 259, No. 3, 1996, pp. 301-303. http://dx.doi.org/10.1016/0014-2999(94)90657-2

[33] J. Komorowska and S. M. Pellis, "Regulatory Mechanisms Underlying Novelty-Induced Grooming in the Laboratory rat,” Behavioural Processes, Vol. 67, No. 2, 2004, pp. 287-293. http://dx.doi.org/10.1016/j.beproc.2004.05.001

[34] C. D. Conrad, K. A. Grote, R. J. Hobbs and A. Ferayorni, "Sex Differences in Spatial and Non-Spatial Y-Maze Performance after Chronic Stress," Neurobiology of Learning and Memory, Vol. 79, 200, pp. 32-40.

[35] S. K. Kulkarni, "Handbook of Experimental Pharmacology,” 3rd Edition, Vallabh Prakashan, Delhi, 2005.

[36] N. P. Murphy, H. A. Lam and N. T. Maidment, "A Comparison of Morphine-Induced Locomotor Activity and Mesolimbic Dopamine Release in C57BL6, 129Sv and DBA2 Mice,” Journal of Neurochemistry, Vol. 79, No. 3, 2001, pp. 626-635.

http://dx.doi.org/10.1046/j.1471-4159.2001.00599.x

[37] G. Porras, P. DeDeurwaerdere, D. Moison and U. Spampinato, "Conditional Involvement of Striatal Serotonin3 Receptors in the Control of in Vivo Dopamine Outflow in the Rat Striatum," The European Journal of Neuroscience, Vol. 17, No. 4, 2003, pp. 771-781. http://dx.doi.org/10.1046/j.1460-9568.2003.02512.x 